\title{
$\alpha 2 p$ controls donor preference during mating type interconversion in yeast by inactivating a recombinational enhancer of chromosome III
}

\author{
Lisa Szeto, ${ }^{1}$ Maria K. Fafalios, ${ }^{1}$ Hualin Zhong, ${ }^{2}$ Andrew K. Vershon, ${ }^{2}$ and James R. Broach ${ }^{1,3}$ \\ ${ }^{1}$ Department of M olecular Biology, Princeton University, Princeton, N ew Jersey 08544-1014 USA; ${ }^{2}$ Waksman Institute and \\ Department of Molecular Biology and Biochemistry, Rutgers University, Piscataway, N ew Jersey 08855-0759 USA
}

Homothallic strains of Saccharomyces cerevisiae can change mating type as often as every generation by replacing the allele at the MAT locus with a copy of mating type information present at one of two storage loci, H ML and H MR, located on either end of chromosome III. Selection of the appropriate donor locus is dictated by a mating type-specific repressor protein, $\alpha 2 p$ : Cells containing $\alpha 2 p$ select H MR, whereas those lacking $\alpha 2 p$ select H ML. As a repressor protein, $\alpha 2 p$ binds to DNA cooperatively with the transcriptional activator Mcmlp. Here we show that two $\alpha 2 \mathrm{p} / \mathrm{Mcm} 1 \mathrm{p}$-binding sites, D PS1 and D PS2, control donor selection. DPS1 and D PS2 are located $30 \mathrm{~kb}$ from the left arm of chromosome III, well removed from HML, HMR, and MAT. Precise deletion of only D PS1 and D PS2 results in random selection of donor loci and in a cells without affecting selection in $\alpha$ cells. Reciprocally, deletion of only the $\alpha 2 \mathrm{p}$ binding segments in each of these two sites results in selection of the wrong donor loci in $\alpha$ cells without affecting preference in a cells. These results suggest that Mcmlp, bound to these two sites in the absence of $\alpha 2 p$, activates $H M L$ as donor. Binding of $\alpha 2 p$ blocks the ability of Mcm1p bound to D PS1 and D PS2 to activate H ML, resulting in default selection of HMR as donor. DPS1 and DPS2 also regulate expression of several noncoding RNAs, although deletion of at least one of these RNA loci does not affect donor preference. This suggests that transcriptional activation, rather than transcription of a specific product, is the initiating event in activating the left arm of chromosome III for donor selection.

[Key Words: S. cerevisiae; mating type interconversion; repression protein $\alpha 2 p$; transcriptional activation; donor selection; recombinational enhancer]

Received May 1, 1997; revised version accepted June 19, 1997.

Mating type interconversion in yeast provides a striking example of developmentally regulated interactions between distant regions of the genome. Most laboratory strains of Saccharomyces exhibit one of two haploid mating types, a or $\alpha$, dictated by the particular al lele, a or $\alpha$, present at a single locus, MAT, on chromosome III. However, those strains that carry the $\mathrm{HO}$ (homothallic) gene do not exhibit a stable mating type but, rather, change mating type as often as every generation (for review, see Herskowitz et al. 1992). The product of the HO gene, a double-stranded DNA endonuclease, initiates this process of mating type interconversion by generating a double-strand break uniquely at a specific site within the MAT Iocus (Strathern et al . 1982; Kostriken et al. 1983; Kostriken and Heffron 1984). The cell then re- pairs this double-strand break by a gene conversion event, inserting at MAT a copy of the DNA present at one of two repositories of mating type information, known as the HML and HMR silent mating type loci. Each of these loci, located at the opposite ends of chromosome III, contains a complete but transcriptionally inactive copy of one mating type allele, with HML normally carrying the $\alpha$ allele and HMR the a allele. Thus, replacement of the a allele at MAT with a copy of the $\mathbf{a}$ allele resident at HMR leads to a switch in mating type (cf. Fig. 1).

The process of mating type interconversion is tightly regulated (Herskowitz et al. 1992). Restricted expression of $\mathrm{HO}$ ensures that switching occurs only during $\mathrm{G}_{1}$ and only in cells that have budded at least once (N asmyth 1983; Breeden and N asymth 1985; Bobola et al . 1996; Sil and Herskowitz 1996). In addition, because HO expression is repressed in diploid cells, switching only occurs in haploids (Jensen and Herskowitz 1984). Finally, cell type dictates which of the silent Ioci, HML or HMR, will 
a Cells
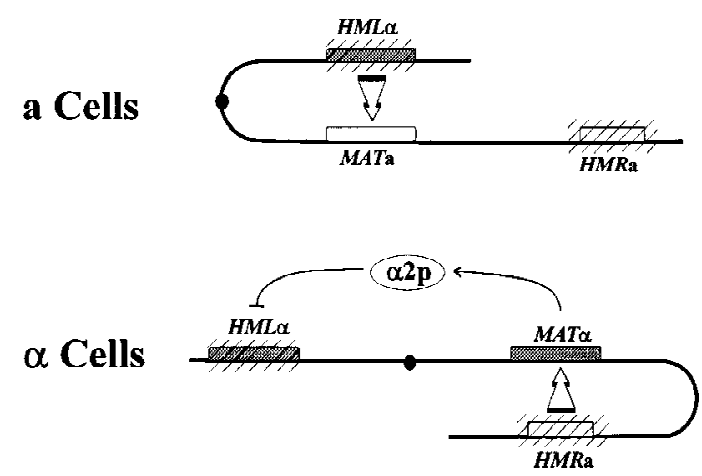

Figure 1. Donor preference during mating type interconversion in Saccharomyces cerevisiae. Diagram of chromosome III indicating the cell-dependent bias in donor preference during mating type interconversion. Mating type loci are indicated by boxes, with filled boxes representing $\alpha$ mating alleles and open boxes representing a mating allel es. The transcriptional ly silent mating type loci, HML and HMR, are denoted by hatching, and the centromere is designated by the filled circle. In a cells (top), HML serves as donor in $\sim 80 \%$ of switching events. In $\alpha$ cells (bottom), the product of the MAT $\alpha 2$ locus, $\alpha 2 p$, blocks HML from serving as donor, and as a consequence, HMR serves as donor in $\sim 95 \%$ of the switching events.

serve as donor following cleavage of the MAT locus. a Cells predominantly use HML as donor, whereas $\alpha$ cells most often use HMR as donor (Herskowitz et al. 1992). Given the disposition of alleles between the two donor loci, this process of donor preference ensures that most $\mathrm{HO}$-initiated events result in a change of mating type, rather than a futile repl acement of the mating type al lele at MAT with the same allele. This regulation requires that the cell be able to promote selective interaction among loci positioned over an entire chromosome.

The fact that the cell exhi bits donor preference in mating type switching indicates that the cell can distinguish HML from HMR in a cell type-specific manner. Cell type-specific recognition of the two loci is dictated by $\alpha 2 p$, one of the two transcriptional regulatory proteins encoded by the MAT $\alpha$ al lele. Cells expressing $\alpha 2 p$ sel ect HMR as donor, whereas cells lacking $\alpha 2 p$ sel ect HML as donor, regardless of the presence or absence of other mating type regulatory proteins (Jensen and Herskowitz 1984; Tanaka et al. 1984; Wu et al. 1996; Szeto and Broach 1997). In haploid cells, $\alpha 2 p$ functions as a repressor of genes, such as STE2 and MFA1, that are responsible for conferring an a mating phenotype to the cell (generically designated aspecific genes). Repression results from the binding of a heteromeric complex, composed of two molecules of $\alpha 2$ protein and two molecules of the constitutively expressed MADS box protein, $\mathrm{Mcmlp}$, to operator sites upstream of the regulated genes (Keleher et al. 1988, 1989; Passmore et al. 1989). These binding sites consist of a 16-bp dyad symmetrical $\mathrm{Mcmlp}$-binding region bracketed by inversely oriented 9-bp $\alpha 2 p$-binding segments (Sauer et al. 1988; Kel eher et al. 1989). Repression requires recruitment of the Tuplp/
Ssn6p general repression complex through direct interaction between $\alpha 2 p$ and Tuplp (Keleher et al. 1992; Komachi et al. 1994). We have recently shown that $\alpha 2 p$ dictates donor preference as a complex with $\mathrm{Mcmlp}$ and through recruitment of Tuplp/Ssn6p (Szeto and Broach 1997). Thus, the same components and interactions required for transcriptional repression by $\alpha 2 p$ are al so essential for cell type-specific donor prefernce.

The particular features of HML or HMR that the cell uses to distinguish between them during mating type interconversion have begun to be clarified. Our previous studies demonstrated that neither the alleles at the donor loci, the structure of these loci, nor any feature near HML, HMR, or MAT provides a marker used by the cell to select one donor locus versus the other during interconversion (Weiler and Broach 1992). Nonetheless, because donor preference is maintained even when MAT is moved to a different chromosome, the two donor loci reside in intrinsically distinct chromosomal domains that control accessibility of the loci in a cell type-specific manner (Weiler and Broach 1992). This observation can be appreciated in the context of recent results from $\mathrm{Wu}$ and Haber (1995), who suggested that the mechanism underlying cell-specific donor preference involves enhanced recombinogenicity of the left arm of chromosome III in a cells versus $\alpha$ cells. In particular, they observed that the frequency of mitotic recombination between heteroalleles of LEU 2, where one allele was inserted at HML and the other at MAT, was 20- to 30-fold higher in a cells than in $\alpha$ cells. They al so observed that HML remained the preferred donor in a cells when situated at several locations within $40 \mathrm{~kb}$ of the left arm of chromosome III but not when positioned further to the right. Thus, Wu and $\mathrm{Haber}$ suggested that enhanced mitotic recombination potential of the left arm of chromosome III in a cells renders HML the preferred donor, whereas this enhanced recombination potential is lost in $\alpha$ cells. In the absence of activated recombination, HMR is the default donor for as yet undefined reasons. Recently, Wu and Haber (1996) identified a small regi on on the left arm of chromosome III significantly removed from MAT or either donor loci that is required to activate enhanced recombination in acel Is. They have desi gnated this region a recombination enhancer.

In this report we present results further defining the cis-acting region on chromosome III responsible for cell type-specific sel ection of donor locus during mating type interconversion. We confirmed the existence of the recombinational enhancer on chromosome III and demonstrated that the activity of this enhancer is dependent on two $\alpha 2 \mathrm{p} / \mathrm{Mcm} 1 \mathrm{p}$-binding sites within this region. We show further that these sites regulate expression of several aspecific RNA transcripts from this domain. Because deletion of the genomic region encoding one of these RNAs does not alter donor preference, transcriptional activation-rather than any particular product of transcription-may be sufficient to stimulate recombination. These results suggest that yeast use a novel mechanism to activate one chomosome arm for donor accessibility during mating type interconversion. 


\section{Results}

A cis-acting site-specifying donor preference resides on the left arm of chromosome III

Because a yeast cell sel ects one mating type donor locus in preference to the other as a function of cell type, the cell is capable of distinguishing $\mathrm{HML}$ from $\mathrm{HMR}$. Because our previous studies indicated that features of chromosome III used by the cell to distinguish $\mathrm{HML}$ from HMR during mating type interconversion are well removed from either locus, we developed a method to systematically survey chromosome III to identify such cis-acting sites. We created a series of inversions within chromosome III, by the procedure described in M aterials and Methods, and then tested strains carrying these inversions for donor preference during normal mating type interconversion. Assuming, for example, that a site on the left arm of chromosome III dictates selection of $\mathrm{HML}$ in a cells, then an inversion with a breakpoint between $\mathrm{HML}$ and this site would yield a strain in which the site is now positioned near HMR rather than HML. Accordingly, in a cells carrying this chromosome, HMR would become the preferred donor. In contrast, if the breakpoint leaves the site associated with $\mathrm{HML}$, then $\mathrm{HML}$ would remain the preferred donor in a cells carrying the inverted chromosome.

Strains carrying different chromosome III inversions were tested for donor preference in both a and $\alpha$ cells, as described in Materials and M ethods, and a summary of this analysis is provided in Figure 2 adjacent to a schematic of each chromosome tested. In the first series of experiments, we held the breakpoint within the right arm of chromosome III constant and varied the position of the breakpoint within the left arm of chromosome III. As evident from these results, proper donor preference in a cells depends on a region located between 24 and $60 \mathrm{~kb}$ on the left arm. That is, the preferred donor in a cells is al ways the locus located immediately distal to the 24- to $60-\mathrm{kb}$ domain. A parallel but reciprocal correlation is evident for donor preference in $\alpha$ cells: The preferred donor locus in $\alpha$ cells is the one removed from the 24- to $60-\mathrm{kb}$ domain. The most straightforward interpretation of these results, in light of the observations from Wu and Haber (1996), is that a single cis-acting site resides between 24 and $60 \mathrm{~kb}$ on the left arm of chromosome III and that this site activates the region around it for recombination in a cells but not in $\alpha$ cells. Data presented below are consistent with this hypothesis.

The additional chromosome III rearrangements are in agreement with the above results, al though they indicate the existence of additional features of the system. In a second set of experiments, we examined the effect of inverting the MAT locus. As evident in Figure 2, neither a local inversion of MAT nor a larger pericentric inversion including MAT alters donor preference in a cells. This is consistent with the model proposed above and with previous results from our laboratory indicating that MAT did not serve as a reference point for donor selection (Weiler and Broach 1992). The reduced efficiency of donor selection in $\alpha$ cells carrying the pericentric inversion and the selection of HML in both cell types in the last two constructs suggests that additional features besides the site between 24 and $60 \mathrm{~kb}$ contribute to donor selection. The implications of these results on donor selection are explored in the Discussion.

Two $\alpha 2 \mathrm{p} / \mathrm{Mcm} 1 \mathrm{p}$-binding sites reside in the donor preference locus on chromosome III

As noted in the introductory section, cell type-specific

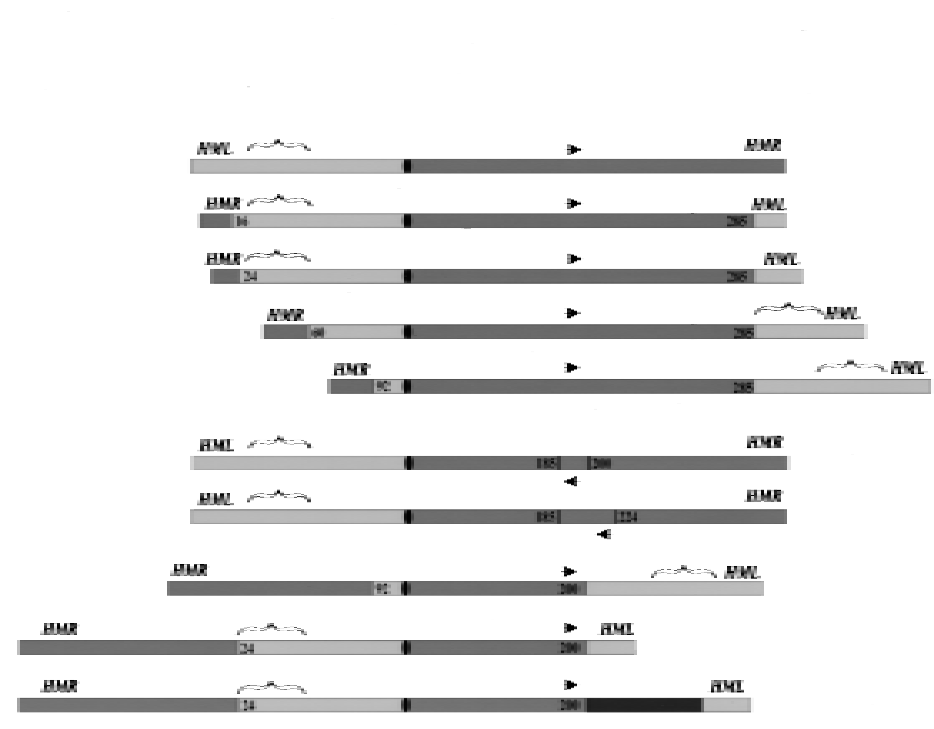

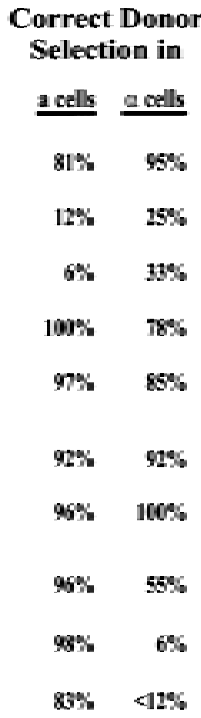

Figure 2. Chromosome inversions reveal a cis-acting site on the left arm of chromosome III required for donor preference. (Left) Diagram of the structure of chromosome III in selected inversion strains. The location of the donor loci, HML and HMR, are indicated, as is the position of the centromere (filled oval) and the MAT locus (arrow). Sequences from the left arm are shaded light gray, and those from the right are shaded dark gray. The positions of the inversion endpoint (in kb from the left arm of the chromosome) are designated on each inversion chromosome. The bracket denotes the region, determined from this analysis, that apparently dictates donor preference. The black segment in the last construct corresponds to $25 \mathrm{~kb}$ of Caulobacter cresentus DNA inserted at the inversion breakpoint. (Right) The proportion of switching events in which the cell selected the appropriate locus (HML for a
represents analysis of at least 25 individual strains, HMR for $\alpha$ strains), determined as described in M aterials and M ethods. Each value represents analysis of at least 25 individual spore clones. Switching events in which the correct donor locus was not selected include those in which the opposite donor was
preferentially selected and those in which no preferential donor locus could be determined. 
donor preference is established by the activity of $\alpha 2 p$ in conjunction with $\mathrm{Mcm} 1 \mathrm{p}$. Accordingly, we examined the 24- to $60-\mathrm{kb}$ region of chromosome III for the presence of sites with homology to known $\alpha 2 \mathrm{p} / \mathrm{Mcm} 1 \mathrm{p}$ binding sites. We found that two such sites reside in this interval, centered at positions 29,209 and 30,595, both of which were noteworthy for several reasons. First, unlike the six known $\alpha 2 \mathrm{p} / \mathrm{Mcm} 1 \mathrm{p}$ sites characterized previously (Zhong and Vershon 1997), neither of these two sites lies immediately upstream of an open coding regi on (cf. Figure 5, below). Second, both of these sites conform to the consensus $\alpha 2 \mathrm{p} / \mathrm{Mcm} 1 \mathrm{p}$-binding motif, deduced from the six previously characterized sites, better than any other sequence within the yeast genome. Finally, these two sites lie in or near the region defined by Wu and Haber (1996) to be involved in donor preference. Thus, these two sites resemble bona fide $\alpha 2 \mathrm{p} / \mathrm{Mcm} \mathrm{cm}$ binding sites, are not associated with expression of a protein product, and reside in a region required for donor preference.

M ost $\alpha 2 p / M c m 1 p$-binding sites are present upstream ( $200 \mathrm{bp})$ of the transcriptional start site of a-specific genes. In the absence of $\alpha 2 \mathrm{p}, \mathrm{M} \mathrm{cmlp}$ binds to these sites and functions as a transcriptional activator. In the presence of $\alpha 2 p, \alpha 2 p$ and $\mathrm{Mcm} 1 \mathrm{p}$ bind cooperatively to the site and repress transcription. To test whether the sequences at 29.2 and $30.6 \mathrm{~kb}$ are authentic $\alpha 2 \mathrm{p} / \mathrm{M} \mathrm{cm} 1 \mathrm{p}$ binding sites, we performed several in vitro and in vivo binding experiments. For in vitro binding assays we synthesized and cloned fragments corresponding to the region from 29,194 to 29,229 (designated DPS1) and to the region from 30,578 to 30,613 (designated DPS2). Each of the cloned fragments was isolated, labeled, and incubated with varying amounts of purified intact $\alpha 2 p$ and constant amount of the purified amino terminal domain (amino acids 1-96) of $\mathrm{Mcmlp}$ (Mead et al. 1996). The proportion of fragment bound by the proteins was then determined by electrophoresis on nondenaturing polyacrylamide gels. As a control, we also tested binding of the equival ent DN A fragment corresponding to the $\alpha 2 \mathrm{p} /$ $\mathrm{Mcm} 1 \mathrm{p}$-binding site from the STE6 promoter, a known

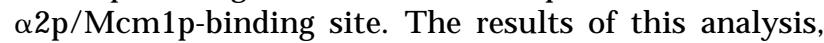
presented in Figure 3, indicate that $\alpha 2 \mathrm{p}$ and $\mathrm{Mcm} 1 \mathrm{p}$ bind individually to both DPS1 and DPS2 with the same relative affinities as they show for the STE6 operator sequence. In addition, they exhibit the same cooperativity in binding to both DPS1 and DPS2 as they do with the STE6 operator.

To confirm that the binding affinities exhibited by DPS1 and DPS2 were physi ologi cally relevant, we examined whether these sites would exert transcriptional repression in vivo in the presence of $\alpha 2 p$ and promote transcriptional activation in the absence of $\alpha 2 p$. To test for $\alpha 2 p-m e d i a t e d$ repression activity, we inserted DPS1 or DPS2 between the upstream activating sequence $C Y C 1$ (USA $\left.{ }_{\mathrm{CYC1}}\right)$ and the TATA element upstream of a CYC1lacZ reporter gene (Acton et al. 1997). The plasmid constructs were then transformed into isogenic $\mathbf{a}$ and $\alpha$ strains, and the expression of the reporter gene determined by assaying $\beta$-galactosidase in individual transfor- mants. The extent of repression was then calculated as the ratio of expression in the $\alpha$ strains carrying the test plasmid to that from the a strain carrying the same plasmid. As evident from the results presented in Figure 4, both DPS1 and DPS2 are as effective in exerting $\alpha 2 p$ dependent repression as is the operator from STE6. We also tested whether these sites would exhibit transcriptional activation in the absence of $\alpha 2 p$. Accordingly, we deleted the $\mathrm{UAS}_{\mathrm{CYC1}}$ from each of the plasmids used in the repression assay and transformed the resulting plasmids into an a strain. The level of $\beta$-galactosi dase elicited by the test plasmid compared to that of a comparable plasmid lacking any UAS elements provided an indication of the transcriptional activation capacity of the $\alpha 2 \mathrm{p} / \mathrm{Mcm} 1 \mathrm{p}$ sites. As shown in Figure 4, both DPS1 and DPS2 possess weak UAS activity, but the level of activation is comparable to that of the STE6 operator. Thus, we conclude that DPS1 and DPS2 are capable of binding $\mathrm{Mcm} 1 \mathrm{p}$ and $\alpha 2 \mathrm{p}$ with affinities comparable to other $\alpha 2 \mathrm{p} /$ $\mathrm{Mcm} l p$-binding sites in the cell and that they are capable of exerting $\mathrm{Mcm}$ lp-mediated transcriptional activation and $\alpha 2 \mathrm{p} / \mathrm{Mcm} 1 \mathrm{p}$-mediated repression in vivo.

\section{DPS1 and DPS2 regulate donor selection}

To test whether DPS1 and DPS2 affect donor preference, we created strains with various deletions spanning these sites and then exami ned donor preference, during normal switching events in strains carrying these del etions. The results of this analysis are summarized in Figure 5 . The largest deletion examined removed both $\alpha 2 \mathrm{p} / \mathrm{Mcm} 1 \mathrm{p}-$ binding sites while retaining the open coding regions flanking the sites. Haploid strains carrying this deletion were viable, indicating that no essential functions resided within the del eted sequences. This del etion had a dramatic effect on donor preference: $\alpha$ cells carrying the deletion exhibited completely normal donor preference-selecting HMR in 95\% of the switching eventsbut a cells carrying the del etion exhibited inverted preference, selecting HMR rather than HML in most of the switching events. Further analysis indicated that both sites contributed to normal switching patterns. A deleti on encompassing DPS1 while retaining DPS2 yiel ded a defect in switching in a cells equivalent to that seen with strains carrying the deletion removing both sites. A deletion spanning DPS2 also reduced efficiency of donor selection in a cells, although not as dramatically as did deletion of the region spanning DPS1. Thus, the region encompassing two $\alpha 2 \mathrm{p} / \mathrm{Mcm} \mathrm{cm}$-binding sites is required for proper donor preference in a cells, al though deletion of this region does not affect switching in $\alpha$ cells.

Given that $\alpha 2 p$ is the principal trans-acting determinant of donor preference, deletion of the region encompassing the $\alpha 2 \mathrm{p} / \mathrm{Mcm} 1 \mathrm{p}$-binding sites DPS1 and DPS2 had an unexpected effect on donor preference. That is, del etions spanning this regi on reversed donor preference in a cells, in which $\alpha 2 p$ was not present, but had no effect on donor preference in $\alpha$ cells, in which $\alpha 2 p$ was present. One explanation for this apparent conundrum is that these sites play an active role in promoting selection of 
A.

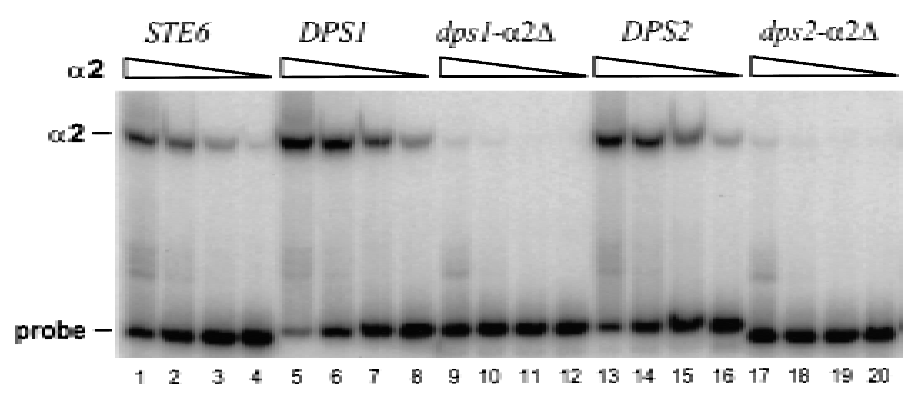

B

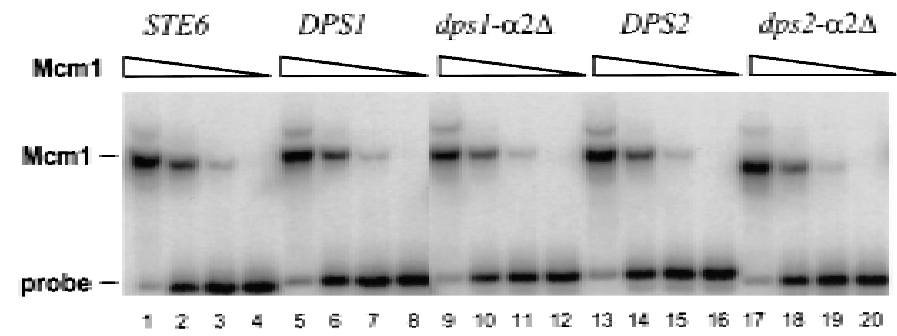

c

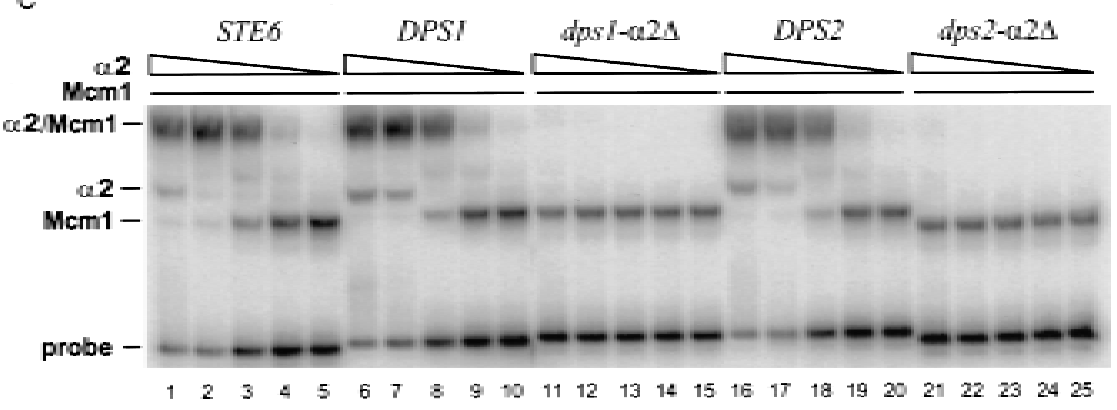

Figure 3. DPS1 and DPS2 bind $\alpha 2 p$ and $\mathrm{Mcm} 1 \mathrm{p}$ in vitro. (A) Binding of $\alpha 2 \mathrm{p}$ to the indicated $\alpha 2 \mathrm{p} / \mathrm{M} \mathrm{cm} 1 \mathrm{p}$ sites (sequences are shown in Table 1) as determined by EM SAs (described in M aterials and M ethods). Purified $\alpha 2 \mathrm{p}$ was added to the binding re actions at $4.0 \times 10^{-7} \mathrm{M}$ (lanes $1,5,9,13,17$ ), $8.0 \times 10^{-8} \mathrm{M}$ (lanes 2,6,10,14,18), $1.6 \times \mathrm{M}$ $10^{-8} \mathrm{M}$ (lanes $\left.3,7,11,15,19\right)$, or $3.2 \times 10^{-9} \mathrm{M}$ (lanes 4,8,12,16,20). (B) Binding of $\mathrm{M} \mathrm{cmlp}$ to the indicated site. Purified M cm1pl-96 fragment was added to the binding reactions at $1.7 \times 10^{-8} \mathrm{M}$ (lanes 1,5,9,13,17), $1.7 \times$ $10^{-9} \mathrm{M}$ (lanes 2,6,10,14,18), $1.7 \times 10^{-10} \mathrm{M}$ (lanes $3,7,11,15,19)$, or $1.7 \times 10^{-11} \mathrm{M}$ (lanes $4,8,12,16,20)$. (C) Binding of $\alpha 2 p$ and $\mathrm{Mcm} 1 \mathrm{p}$ to the indicated site. Pruified $\alpha 2 \mathrm{p}$ was added to the binding reactions at $8.0 \times 10^{-8} \mathrm{M}$ (lanes 1,6,11,16,21), $1.6 \times 10^{-8} \mathrm{M}$ (lanes 2,7,12,17,22), $3.2 \times 10^{-9} \mathrm{M}$ (lanes 3,8,13, 18,23), $6.4 \times 10^{-10} \mathrm{M}$ (lanes $4,9,14,19,24$ ), or $1.3 \times 10^{-10} \mathrm{M}$ (lanes 5,10,15,20,25).

Figure 4. DPS1 and DPS2 can mediate cell type-specific transcriptional activation and repression in vivo. The $\alpha 2 \mathrm{p} / \mathrm{Mcm} \mathrm{cp}$ binding sites listed on the left (sequences shown in Table 1) were inserted into the assay vectors indicated at the top and tested for repression activity (A) or activation activity (B), as described in Materials and Methods. (A) $\beta$-Galactosidase levels were determined on three independent transformants of the indicated plasmid in strain EG 123 (astrain) and strain 246.1.1 ( $\alpha$ strain). Values are the average of the three determinations. Repression ratio is the activity obtained in the a strain containing the indicated plasmid divided by the activity obtained in the $\alpha$ strain containing the same plasmid. (B) $\beta$-Galactosidase levels were determined on three independent transformants of the indicated plasmid in strain EG123 (a strain). Activation ratio was calculated by dividing the $\beta$-galactosidase activity obtained with the plasmid containing the indicated site by that obtained with the plasmid lacking any site. 
Figure 5. $\alpha 2 \mathrm{p} / \mathrm{Mcm} \mathrm{cm}$-binding sites on the left arm of chromosome III dictate donor preference in a cells. (Top) A diagram of chromosome III is shown which indicates the positions of HML, HMR, MAT (arrowhead), the centromere (filled oval), the left arm (light gray) and the right arm (dark gray). The positions of the three mating type loci and the centromere are specified (in kb from the left end of the chromosome). (Middle) The region from 26 to $35 \mathrm{~kb}$ of chromosome III is expanded to show the positions of the two $\alpha 2 p /$ $\mathrm{Mcm}$ lp-binding sites (shaded circles) and the adjacent open reading frames (shaded rectangles, taper at the $3^{\prime}$ end of the reading frame). (Bottom) The segment of chromosome III from 29.5 to $31 \mathrm{~kb}$ present in the wild-type (first line) and in several deletion strains, indicating the locations of the two $\alpha 2 \mathrm{p} / \mathrm{Mcm} \mathrm{cp}$ sites $(\bullet)$ and the regions del eted in each strain. To the right of each chromosome segment is indicated the proportion of switching events in which the cell selected the appropriate locus (HML for astrains; HMR for $\alpha$ strains), determined as described in $M$ aterials and Methods.

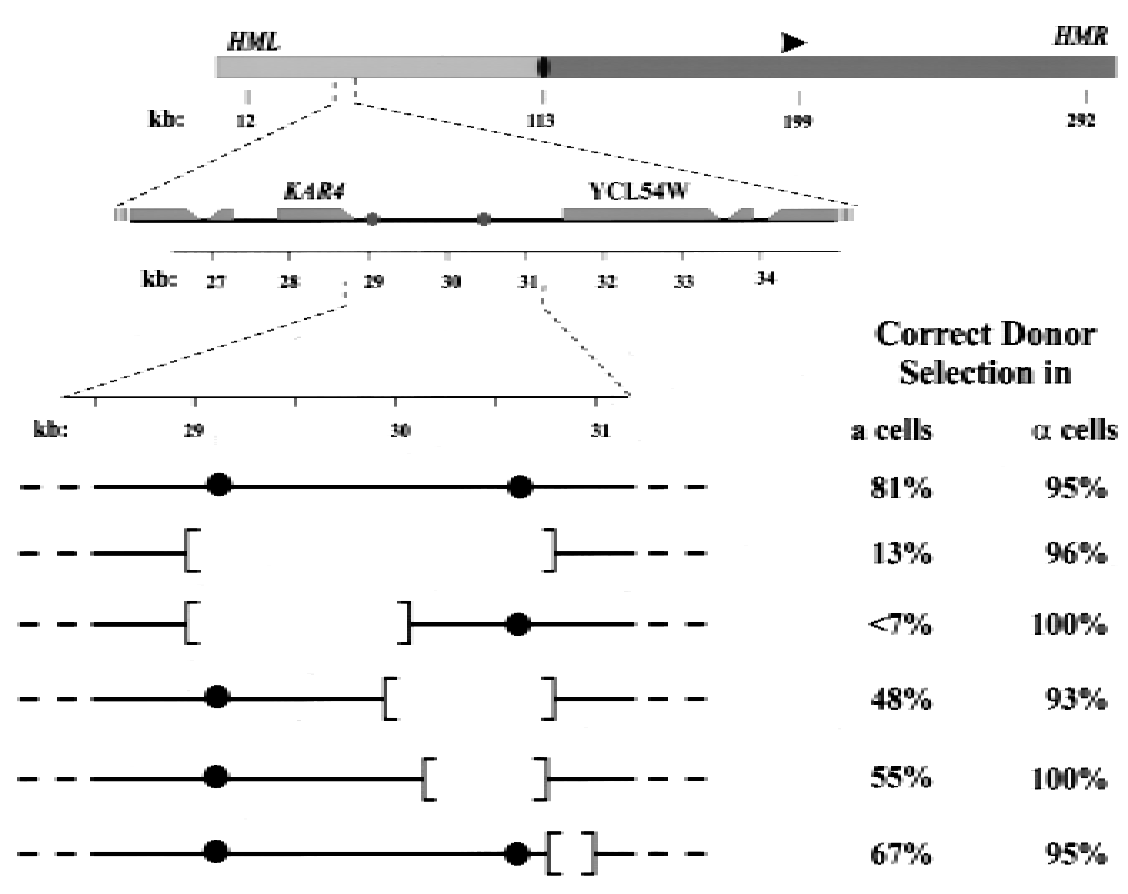

$\mathrm{HML}$ in a cells and that this function is repressed by the binding of $\alpha 2 p$ to the sites. This model is consistent with our observation (Szeto and Broach 1997) that donor selection in the presence of $\alpha 2 p-a$ preference for HMR over HML-is the same as that obtained by deletion of the sites.

To test this hypothesis, we created several specific alleles of DPS1 and DPS2 and then tested their effect on donor preference in $\mathbf{a}$ and $\alpha$ cells. We first precisely de- leted either or both $\alpha 2 \mathrm{p} / \mathrm{Mcm} 1 \mathrm{p}$-binding sites (cf. Table 1 ) and then examined donor preference in the resulting three strains. As evident from Table 2, deletion of DPS1 al one had a small but significant effect on donor preference in a cells and a minor effect on donor preference in $\alpha$ cells. Deletion of DPS2 had no detectable effect on donor preference in either cell type. Deletion of both DPS1 and DPS2, leaving the remainder of this region intact, rendered donor preference completely random in

Table 1. $\alpha 2 \mathrm{p} / \mathrm{Mcm} 1 \mathrm{p}$ sites and plasmids used in this study

\begin{tabular}{|c|c|c|c|}
\hline \multirow[b]{2}{*}{ Site } & \multirow[b]{2}{*}{ Sequence } & \multicolumn{2}{|c|}{ Plasmid } \\
\hline & & repress & activate \\
\hline STEK & tcgaCATGTAATTACCTAATAGGGAAATTTACACGtcga & $\mathrm{pHZ13}$ & pHZ84 \\
\hline DPSI & tCgaGCCATGTAATTACTTAAATAGGAAGTTTACACGATtcga & $\mathrm{pHZ108}$ & pHZ121 \\
\hline$d p s 1-\alpha 2 \Delta$ & tcgaGCCAGCTGATTACTTAAATAGGAAGTTCGGCCGATtcga & $\mathrm{pHZ} 112$ & pHZ128 \\
\hline$D P S 2$ & tcgaAT CGTGTAATTACTGTATTGGGAAATTTACACGATTtaga & $\mathrm{pHZ106}$ & pHZ122 \\
\hline$d p s 2-\alpha 2 \Delta$ & ATTACTGTATTGGGAAATT & $\mathrm{pHZ} 115$ & $\mathrm{pHZ} 125$ \\
\hline
\end{tabular}

U ppercase letters represent the sequences of the genomic $\alpha 2 \mathrm{p} / \mathrm{Mcm} 1 \mathrm{p}$ sites from the loci listed on the left that were cloned into the plasmids listed on the right to test for transcriptional repression (repress) and transcriptional activation (activate activity), results from which are presented in Fig. 4. Lowercase letters represent nucleotides that were added to facilitate cloning into the plasmid. U nderlined sequence represents the $\mathrm{Mcm} 1 \mathrm{p}$-binding domain at each site; the ital icized sequence represents the $\alpha 2 p$-binding domains. The sequences of the mutant alleles of DPS1 and DPS2 are also shown, indicating the altered (bold) or deleted (space) base pairs. The mutation on the left side of dpsl created a Clal restriction site; the mutation on the right side of dpsl created a BstBI restriction site; the mutation on the left side of dps2 created a Pvull restriction site; the mutation on the right side of dps2 created an Eagl site. These restriction sites were used to verify the presence of the mutant alleles in every spore clone used in donor preference analysis. 
Table 2. $\alpha 2 \mathrm{p} / \mathrm{Mcm} 1$ sites mediate donor preference

\begin{tabular}{|c|c|c|c|c|c|}
\hline \multirow[b]{3}{*}{ Strain } & \multirow[b]{3}{*}{ Allele $e^{a}$} & \multicolumn{4}{|c|}{ Donor selection ${ }^{b}$} \\
\hline & & \multicolumn{2}{|c|}{ in a cells } & \multicolumn{2}{|c|}{ in $\alpha$ cells } \\
\hline & & $\mathrm{HML}$ & HMR & HMR & $\mathrm{HML}$ \\
\hline Y2201 & wild type & $81 \%(152)$ & $13 \%(24)$ & $95 \%(239)$ & $2 \%(6)$ \\
\hline Y 2388 & $\mathrm{dps} 1 \Delta$ & $68 \%(13)$ & $26 \%(5)$ & $84 \%(16)$ & $11 \%(2)$ \\
\hline Y2389 & $\mathrm{dps} 2 \Delta$ & $86 \%(18)$ & $10 \%(2)$ & $100 \%(28)$ & $0 \%(0)$ \\
\hline Y2390 & $\mathrm{dps} 1 \Delta \mathrm{dps} 2 \Delta$ & $30 \%(7)$ & $26 \%(6)$ & $75 \%(46)$ & $7 \%(4)$ \\
\hline Y 2391 & dps1- $\alpha 2 \Delta$ & $95 \%(21)$ & $0 \%(0)$ & $70 \%(28)$ & $23 \%(9)$ \\
\hline Y 2392 & dps2- $22 \Delta$ & $87 \%(26)$ & $3 \%(1)$ & $90 \%(18)$ & $5 \%(1)$ \\
\hline Y2393 & dps1- $\alpha 2 \Delta$ dps2- $22 \Delta$ & $79 \%(30)$ & $5 \%(2)$ & $23 \%(9)$ & $55 \%(22)$ \\
\hline Y 2394 & dps1 $1 \Delta-d p s 2 \Delta$ [DPS1 DPS2] & $40 \%(4)$ & $50 \%(5)$ & $61 \%(17)$ & $4 \%(1)$ \\
\hline
\end{tabular}

${ }^{a}(d p s 1 \Delta)$ Substitution of the sequence GGATCC for the 31 bp of chromosome III from position 29,194 to 29,224; (dps2 2 ) substitution of the sequence GGATCC for the 31 bp of chromosome III from position 30,580 to 30,610; (dps1- $\alpha 2 \Delta$, dps2- $\alpha 2 \Delta$ ) sequences shown in Table 1. Strain Y 2394 consists of strain Y 2390 containing a centromeric plasmid carrying the 5.33-kb BamHI fragment spanning DPS1 and DPS2.

bDonor preference was determined as described in Materials and M ethods by examining the predominant allele at MAT in colonies derived from individual spores of the indicated cell type with the designated inversion obtained following dissection of the indicated strain. N umbers in parentheses are the absolute number of spore clones that had selected the designated donor during mating type interconversion. Only those colonies that gave a single predominant MAT allele are listed. The remainder for each strain represents colonies in which both donor alleles were represented essentially equally in the spore clone.

a cells while causing little or no effect on donor preference in $\alpha$ cells. Thus, we conclude that the two $\alpha 2 \mathrm{p} /$ Mcmlp sites act redundantly to promote selection of $\mathrm{HML}$ in a cells. We note that deletion of only DPS1 and DPS2 does not yield as severe a donor preference phenotype as does deletion of the entire region spanning the two sites. This suggests that the recombination enhancer consists of more than just these two sites, a hypothesis elaborated in the Discussion.

In a second series of experiments, we examined the effects on donor preference of alleles of DPS1 and DPS2 in which we had ablated both $\alpha 2 p$-binding regions at each locus while leaving the $\mathrm{Mcm} / \mathrm{p}$-binding region intact. As a control for these experiments, we first tested these alleles for the ability to bind $\mathrm{Mcm} 1 \mathrm{p}$ and $\alpha 2 \mathrm{p}$ in vitro and promote transcriptional activation and repression in vivo. As evident from the gel shift assays shown in Figure 3, both sites were capable of binding $\mathrm{Mcm} 1 \mathrm{p}$ with the same affinity as that of the corresponding wildtype allele. However, both mutant sites exhibited at least a 100 -fold reduction in their ability to bind $\alpha 2 p$. These results were confirmed in the in vivo transcriptional assay. As shown in Figure 4, both mutant alleles promoted transcriptional activation of the $\mathrm{CYCl}$ reporter with the same or better efficiency than did the corresponding wild-type alleles or the cognate site from STE6. However, neither of the alleles exhibited any $\alpha$-specific repression activity. Thus, both mutant alleles retained their ability to promote transcriptional activation but could not exert $\alpha$-specific transcriptional repression.

The donor preference during mating type interconversion of strains carrying either or both of these mutant al leles is presented in Table 2. Introduction of either mutant al lele al one had no appreciable effect on donor pref- erence in either a cells or $\alpha$ cells. However, strains carrying these mutant alleles at both sites exhibited normal donor preference in a cells but now showed an inverted donor selection in $\alpha$ cells. This suggests that $\alpha 2 \mathrm{p}$ binding to either site restricts selection of HML. This result is the reciprocal of that observed above for strains in which the sites are completely deleted. From these mutant studies, we conclude that DPS1 and DPS2 play an active role in donor selection in a cells and that binding of $\alpha 2 p$ renders these sites inactive for donor sel ection.

\section{DPS1 and DPS2 regulate a-specific transcripts}

Given the strict correlation in the structural require ments of $\alpha 2 \mathrm{p} / \mathrm{Mcm} 1$ for both donor preference and transcriptional repression, we examined whether DPS1 or DPS2 regulates transcription within the region of the recombination enhancer. We isolated total RNA from two different pairs of isogenic $\mathbf{a}$ and $\alpha$ strains containing an intact recombination enhancer and from $\mathbf{a}$ and $\alpha$ strains deleted specifically for DPS1 and DPS2. Gel-fractionated RNA was probed with DNA corresponding to different regions across the recombination enhancer domain, the results of which are presented in Figure 6. As evident from these results, the two genes flanking the enhancer region, KAR4 and YCL54W, are transcribed at essentially equal levels in both a and $\alpha$ cells. However, several transcripts that derive from the enhancer region exhibit an acell-specific pattern of expression. The orientation and initiation sites of these transcripts were determined by RNase protection and primer extension assays (data not shown) and are indicated on the schematic diagram at the bottom of Figure 6. Transcription of a $0.3-\mathrm{kb}$ species initiates at a site $250 \mathrm{bp}$ to the right of DPS2, occurs only in a cells, and is dependent on the 
Figure 6. Transcription within the recombination enhancer. Samples $(20 \mu \mathrm{g})$ of total RNA isolated from the indicated strains were fractionated on formaldehyde-agarose gels, transferred to nylon membranes, and hybridized with ${ }^{32} \mathrm{P}-\mathrm{la}-$ beled probes corresponding to positions 26,740-30,145 (left), 29,963-30,803 (middle),or 30,803-31,955 (right) of chromosome III. Orientation and precise positions of RNA species homologous to these fragments were determined by RN ase protection assays and are indicated at the bottom on a diagram of a 26- to 35-kb segment of chromosome III [(shaded circles) DPS1 and DPS2; (shaded rectangles) open coding regions, taper at the $3^{\prime}$ end of the reading frame]. (Bottom panels) Hybridization filters were stripped and reprobed with DN A specific for actin mRN A. Strains: (wt) 14a (ahis1) and 17 $\alpha$ ( $\alpha$ his1); DPS1 DPS2, a and $\alpha$ spore clones of a ho::U RA 3 derivative of strain Y2201; dps1 dps2, a and $\alpha$ spore clones of an ho::U RA 3 derivative of strain Y2390.

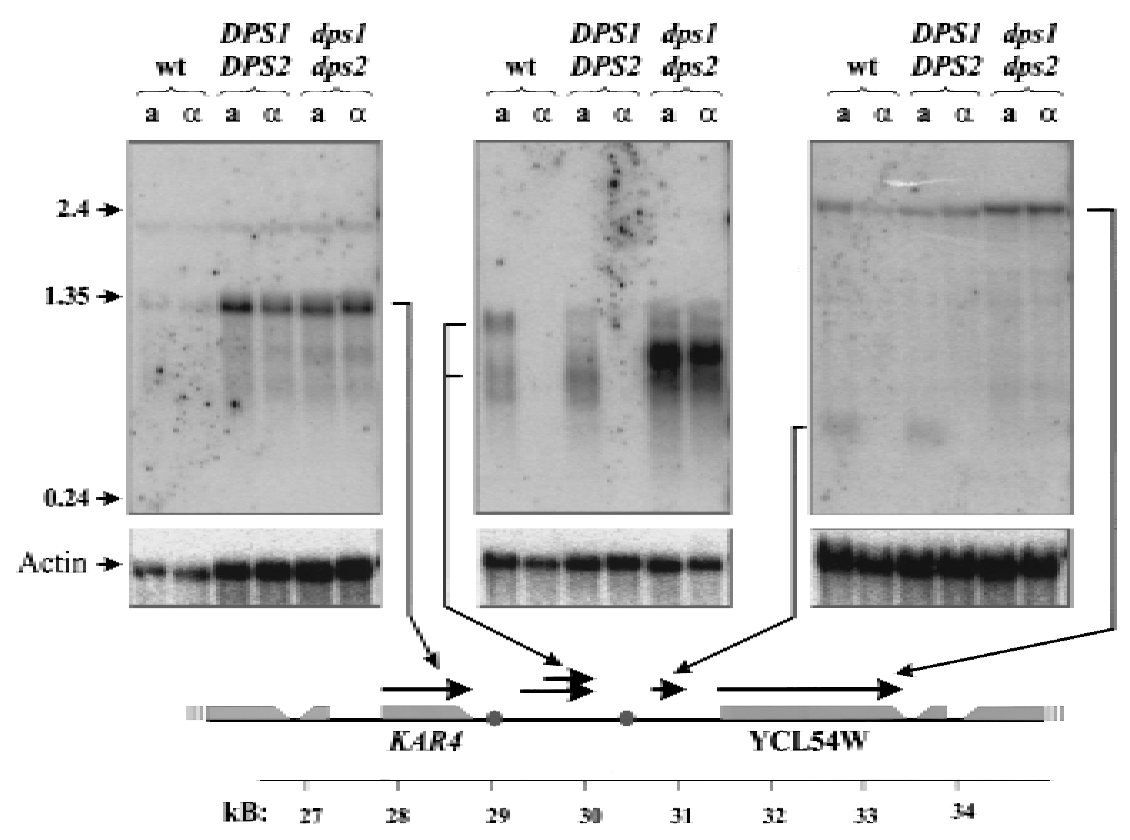

presence of DPS1 and/or DPS2. Transcription from the regi on lying between DPS1 and DPS2 is somewhat more complex. a-Specific trancripts ranging in size from 0.3 to $1.1 \mathrm{~kb}$ that derive from this region are evident in two different strains, although the relative amounts of the different species differs in two different strains. Because strains carrying deletions of DPS1 and DPS2 contain transcripts over this region not seen in DPS1 ${ }^{+}$PPS2 $^{+}$ strains, we cannot readily determine whether the aspecific transcripts are dependent on these two sites. $\mathrm{N}$ one of the a-specific transcripts encompasses an extended open coding region, and all of these transcripts are at low abundance: By quantitative RN ase protection assays, none of the transcipts has a steady-state level higher than that of the $\alpha 2$ mRNA (data not shown).

\section{The recombination enhancer acts in cis}

The fact that specific RN A species are transcribed from the recombination enhancer raises the possibility that these species could be diffusible elements of the donor preference machinery. Accordingly, we asked whether specific mutations of the recombination enhancer could be complemented in trans. As noted in Table 2, a cells deleted specifically for DPS1 and DPS2 select a donor locus during mating type interconversion essentially randomly. In addition, these cells show reduced expression of at least one of the a-specific RNA species transcribed from this region. We introduced into this strain a centromeric plasmid carrying a fragment spanning DPS1, DPS2, and the two a-specific RN A-transcribed regions. As evident from the data in Table 2 , the presence of the plasmid did not correct the donor preference defect resulting from deletion of the two $\alpha 2 \mathrm{p} / \mathrm{Mcm} 1 \mathrm{p}$ sites.
Thus, if any of these two RNA species are involved in donor selection, they apparently cannot be provided in trans.

\section{Discussion}

The nature of the donor preference locus

We have shown in this study that two $\alpha 2 \mathrm{p} / \mathrm{Mcm}$ 1p-binding sites play critical roles in the function of the recombination enhancer on chromosome III responsible for donor preference during mating type interconversion. Specific deletion of both of these sites renders donor preference in a cells completely random while having no effect on donor preference in $\alpha$ cells. In contrast, inactivation of the $\alpha 2 p$-binding domains from these loci, which alleviates $\alpha 2 p$-mediated repression while retaining the transcriptional activation potential of the sites, has the opposite effect: Donor preference is normal in a cells but completely inverted in $\alpha$ cells. These results indicate that in the absence of $\alpha 2 p$ these two sites re dundantly play a positive role in promoting enhanced recombination. The presence of $\alpha 2 p$ abrogates this enhanced recombination potential. Because $\alpha 2 p$ had no effect on the frequency of selecting HMR in $\alpha$ cells carrying the enhancer near HMR only (data not shown), we can conclude that $\alpha 2 p$ bound to the enhancer does not promul gate a negative recombination potential. Rather, the enhancer el evates the recombination potential of the surrounding chromosomal domain when $\alpha 2 p$ is absent but does not affect the intrinsic recombination potential of a region when $\alpha 2 p$ is present.

Although the $\alpha 2 \mathrm{p} / \mathrm{M} \mathrm{cmlp}$-binding sites are necessary for proper donor sel ection, they are not sufficient. In mo- 
lecular dissections of the enhancer region performed by Wu and Haber (1996), a segment just encompassing DPS1 was insufficient to impart donor preference activity. Rather, reasonable activity required not only DPS1 but al so the centromere-proximal 500-bp region adjacent to DPS1. In addition, we find that precise deletion of both DPS1 and DPS2 does not yield as severe a phenotype as does del etion of the entire domain spanning both DPS1 and DPS2: The former del etion yields random selection of donor sites while the latter deletion yields a complete bias for HMR as donor in a cells. From these observations, we conclude that the donor preference locus, or recombination enhancer, consists of two elements: a cell type-regulated transcriptional enhancer (which can be provided either by DPS1 or DPS2), and a second element of unknown function. The fact that deletion of the entire locus was a more severe phenotype than deletion of DPS1 and DPS2 alone suggests either that this second element has intrinsic activity in the absence of a transcriptional enhancer or that some other transcriptional activation element resides in this region. As discussed below, this second element could be the coding domain for a cis-acting RN A or, more likely, the entry site for a recombination-promoting complex capable of diffusion along the chromosome.

\section{Why is HMR the default donor locus?}

Although the presence of a cell type-specific recombination enhancer on the left arm of chromosome III accounts for preferential selection of $\mathrm{HML}$ in a strains, the reason for the preference for $\mathrm{HMR}$ in $\alpha$ strains is not as clear. As noted above, because del eting the recombination enhancer or placing it near HMR has no effect on donor preference in $\alpha$ cells (data not shown), we conclude that the enhancer does not act to repress selection of $\mathrm{HML}$ in $\alpha$ cells. This would suggest that in the absence of activation of $\mathrm{HML}$ for recombination, HMR is intrinsically more recombinogenic during mating type interconversion than is HML. This intrinsically higher recombinational potential of HMR could be attributable to the local chromosomal context of HMR or to its position relative to MAT. Because previous studies have documented that HMR is the preferred donor in $\alpha$ cells even when MAT resides on a separate chromosome, local context plays a role in selection of HMR (Weiler and Broach 1992; Wu et al. 1996). However, as noted from the data in this study, the position of HMR relative to MAT also contributes to the intrinsic donor preference in $\alpha$ cells. In the normal chromosomal context, MAT is twice as far from HML as from HMR. In strains carrying a chromosome III inversion in which this ratio is inverted, donor preference in $\alpha$ cells becomes random (Fig. 2, line 8), and in strains carrying an inversion chromosome that places MAT much nearer HML than HMR, HML is the preferred donor in $\alpha$ cells (Fig. 2, line 9). In these inversions, the $100-k b$ chromosomal context in which HMR is embedded remains unchanged from that in wild-type cells, indicating that local context does not override relative position. Thus, we conclude that both relative position and local context collaborate to establish HMR as the pre ferred donor in the absence of activation of the recombination enhancer.

\section{Models for the role of $\alpha 2 p$ in donor preference}

We can envision two classes of models that account for the role in donor preference of $\alpha 2 p$ and the two $\alpha 2 p /$ $\mathrm{Mcm}$ lp-binding sites within the recombination enhancer on chromosome III. These are diagrammed on Figure 7. The first model suggests that DPS1 and DPS2 regulate transcription of one or more RNAs that act in cis, spreading outward al ong the chromosome from their site of synthesis to enhance the recombinational potential of DNA with which they are associated. How such an RNA or RNAs would promote recombination is not known, al though RNA as a recombination enhancer is not unprecedented (Kotani et al. 1996; Y oon et al. 1996). Several precedents exist for cis-acting RNAs that profoundly affect the behavior of the associated chromosome. Xist RN A, transcribed from the XIC Iocus on the inactive $X$ chromosome, coats the inactive $X$ chromosome and is required for its inactivation (Brown et al. 1992; Rastan 1994; Penny et al. 1996). Similarly, genes encoding structural RN As of unknown functional reside within all known regions of mammalian genomes known to be subject to parental imprinting, circumstantially implicating these RN As in chromosomal imprinting. An attractive feature of this model is that it readily accounts for the strict correlation between the roles of $\alpha 2 p$ in transcriptional regulation and donor preference.

The second model postulates that the recombination

A

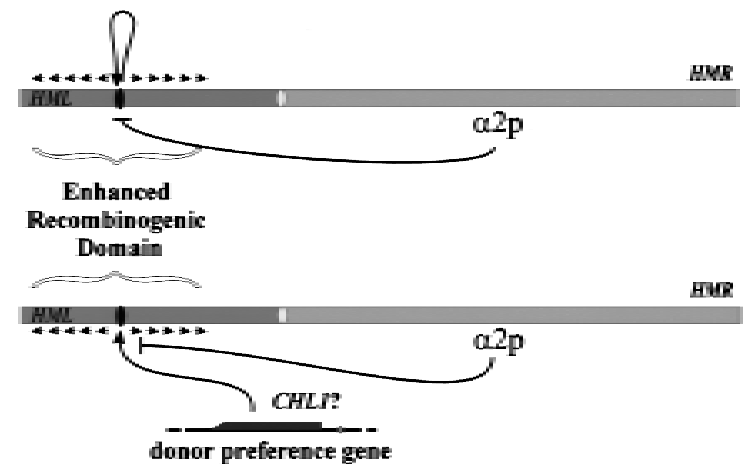

Figure 7. Two models for the role of $\alpha 2 p$ in donor preference. (A) Cis-acting RNAs. One or more RNA species from the recombination enhancer domain expressed in a cells associates with the left arm of chromosome III to promote enhancer recombination potential of the underlying DNA. Repression of expression of these RNAs by $\alpha 2 p$ abrogates the enhanced recombination potential of the left arm in $\alpha$ cells. (B) Loading recombination proteins. In a cells, the recombination enhancer provides a loading site for one or more proteins, possibly Chl lp, that spread outward along the left arm of chromosome III and promote enhanced recombination. Alteration of the chromatin structure of the enhancer domain by $\alpha 2 p$ precludes access of the recombination proteins to the loading site to preclude enhanced recombination in $\alpha$ cells. 
enhancer serves as an entry site for loading a protein or complex onto chromosome III, which then spreads outward along the chromosome from the site to promote enhanced recombination in the region surrounding the site. One candidate for such a protein is the product of the $\mathrm{CHL} 1$ locus. Deletion of this gene renders donor preference random in a cells but has no effect on donor preference in $\alpha$ cells (Weiler et al. 1995). The function of the $\mathrm{Chl} 1 \mathrm{p}$ in donor preference is unknown, but the protein exhibits significant homology to Rad3p, a DN A helicase (Gerring et al. 1990). Thus, we might postulate that Chl 1p would enhance recombination by promoting strand exchange when present on the chromatin in the vicinity of a donor locus.

In this model we presume that the entry site for the recombination complex would be the second element of the recombinati on enhancer discussed above. A ccessibility of this site would be dependent of the transcriptional activation potential of DPS1 and DPS2: In a cells DPS1 and DPS2 would function as activators to render the site accessi ble to the complex, and in $\alpha$ cells DPS1 and DPS2 would function as repressors to make the site refractory. Transcription of the locus in a cells could be required for opening the chromatin to allow entry of the complex. Alternatively, such transcription could simply be coincidental, because of the fact that activating the chromatin structure for entry of the complex could render the local region accessible to the basal transcriptional apparatus. In either event, binding of $\alpha 2 p$ to DPS1 or DPS2 would preclude entry of the complex by repressing transcription or by converting the local chromatin structure into a "closed" configuration. In either case, this would likely involve a Tuplp/Ssn6p-mediated organization of phased nucleosomes emanating outward from DPS1 and DPS2 (Cooper et al. 1994; Szeto and Broach 1997).

Correlation between selective recombination and transcriptional activation has also been noted in hematopoi etic lineages. In heavy-chain class switching in B cells, transcription occurs in the $5^{\prime}$ region of one of the heavy-chain constant domains prior to selection of that particular domain for recombination. Ultimately, the transcriptionally activated constant domain is joined to the previously matured variable domain to generate a new heavy chain (Yancopoulos et al. 1986; Jung et al. 1993; Zhang et al. 1993). Thus, transcription marks the prospective recombination site. Similarly, the recombination machinery-Ragl, Rag2, Ku, and so forth-responsible for rearrangements of immunoglobul in genes in B-cell lineages is the same as that required for rearrangement of $\mathrm{T}$-cell receptor genes in $\mathrm{T}$-cell lineages. $\mathrm{N}$ onethel ess, only immunogl obulin genes are rearranged in B cells and only T-cell receptor genes are rearranged in $\mathrm{T}$ cells. In both cell types, transcription occurs in the region subject to recombination but not in the region repressed for recombination (Stanhope-Baker et al. 1996). In neither of these cases is the functional relationship between transcription and recombination known: Transcription may serve to activate the locus or domain for the recombination event or it may be a by-product of "opening" the chromatin over this region to allow re- combination. The experimental accessibility of theyeast donor preference locus may allow resolution of the nature of the correlation in at least this one case.

\section{Materials and methods}

Strains and plasmids

All of the strains used in this study were derived from strain LS255, a cir ${ }^{\circ}$ derivative (Rose and Broach 1990) of strain Y 2201 (Szeto and Broach 1997) and are listed in Table 3. Inversions were induced using the FIplp recombinase and Flplp recognition target (FRT) sites from the yeast $2 \mu$ circle plasmid. Plasmids pKSW42 and pKSW43 were used to introduce FRT sites in inverted orientation into chromosome III at the endpoints of the

Table 3. Strains used in this study

\begin{tabular}{|c|c|}
\hline Strain & Genotype $^{a}$ \\
\hline LS255 & $\begin{array}{l}\mathrm{hml} \alpha 1 \alpha 2 \Delta \text {-inc/hml } \alpha 1 \alpha 2 \Delta \text {-inc MATa/ } \\
\text { MAT } \alpha \text { hmral } 101-\text { inc/hmral } \Delta 101-i n c ~ H O / H O \\
\text { leu2-3,112/leu2-3,112 his3 } 1 / \text { his3 } 1 \\
\text { ura3-52/ura3-52 trp1-289/trpl-289 }\end{array}$ \\
\hline Y2365 & LS255, MATa/MAT $\alpha$-inv(16-285 kb) \\
\hline Y2366 & LS255, MATa-inv(16-285 kb)/MAT $\alpha$ \\
\hline Y2367 & LS255, MATa/MAT $\alpha-i n v(24-285 \mathrm{~kb})$ \\
\hline Y2368 & LS255, MATa-inv(24-285 kb)/MAT $\alpha$ \\
\hline Y2369 & LS255, MATa/MAT $\alpha-i n v(60-285$ kb) \\
\hline Y2370 & LS255, MATa-inv(60-285 kb)/MAT $\alpha$ \\
\hline Y2371 & LS255, MATa/MAT $\alpha-i n v(92-285 \mathrm{~kb})$ \\
\hline Y2372 & LS255, MATa-inv(92-285 kb)/MAT $\alpha$ \\
\hline Y2373 & LS255, MATa/MAT $\alpha-i n v(185-200$ kb) \\
\hline Y2374 & LS255, MATa-inv(185-200 kb)/MAT $\alpha$ \\
\hline Y2375 & LS255, MATa/MAT $\alpha-i n v(185-224$ kb) \\
\hline Y2376 & LS255, MATa-inv(185-224 kb)/MAT $\alpha$ \\
\hline Y2377 & LS255, MATa/MAT $\alpha-i n v(92-200$ kb) \\
\hline Y2378 & LS255, MATa-inv(92-200 kb)/MAT $\alpha$ \\
\hline Y2379 & LS255, MATa/MAT $\alpha-i n v(24-200 \mathrm{~kb})$ \\
\hline Y2380 & LS255, MATa-inv(24-200 kb)/MAT $\alpha$ \\
\hline Y2381 & LS255, MATa/MAT $\alpha-i n v(24-200$ kb)::pLS41 \\
\hline Y 2382 & LS255, MATa-inv(24-200 kb)::pLS41/MAT $\alpha$ \\
\hline Y 2383 & 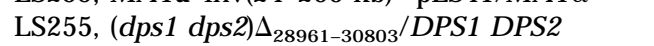 \\
\hline Y2384 & LS255, dps1 $\Delta_{28961-30183} /$ DPS1 \\
\hline Y2385 & 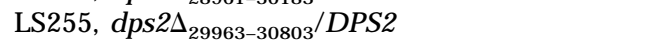 \\
\hline Y2386 & LS255, dps $2 \Delta_{30145-30739} / \mathrm{DPS} 2$ \\
\hline Y2387 & LS255, DPS2 $\Delta_{30739-30997 / D P S 2}$ \\
\hline Y2388 & LS255, dps1 $\Delta / D P S 1$ \\
\hline Y2389 & LS255, dps2 2 /DPS2 \\
\hline Y2390 & LS255, dps1 $\Delta$ dps2 2 /DPS1 DPS2 \\
\hline Y2391 & LS255, dps1- $\alpha 2 \Delta / D P S 1$ \\
\hline Y2392 & LS255, dps2- $\alpha 2 \Delta / D P S 2$ \\
\hline Y2393 & LS255, dps1- $\alpha 2 \Delta$ dps2- $\alpha 2 \Delta /$ DPS1 DPS2 \\
\hline Y 2394 & $\begin{array}{l}\text { LS255, dps1 } 1 \text { dps2 } 2 \text { /DPS1 DPS2 [YCp-DPS1- } \\
\text { DPS2] }\end{array}$ \\
\hline 246.1 .1 & MAT $\alpha \operatorname{trp} 1$ leu2 ura3 his4 \\
\hline EG123 & MATa trp1 leu2 ura3 his4 \\
\hline GY 12 & MATa his4-917 lys2-128 leu2 ura3-52 nrp2-1 \\
\hline
\end{tabular}

aStrains Y 2365-Y 2382 each contain an inversion within the indicated chromosome III homolog with the indicated inversion endpoints. Chromosome III in strains Y 2381 and Y 2382 carries $25 \mathrm{~kb}$ of $\mathrm{C}$. crescentus DN A inserted at the inversion breakpoint between HML and MAT. Deletion alleles in strains Y2388Y2394 are described in the footnote to Table 2. 
desired inversions. Plasmid pKSW42 is a derivative of pUC18 containing a 674-bp HindlII-BamHI spanning FRT and a 1106bp HindllI-Aval frament containing the URA 3 gene. Plamid pKSW43 is a derivative of pUC18 with the same FRT site and a 1764-bpBamHI fragment carrying the HIS3 gene. Approximately 1-kb DN A segments corresponding to the endpoints of the desired inversion were obtained by PCR amplification and cloned separately into plamsids pKSW32 and pKSW43. The resulting plasmids were digested with a restriction enzyme unique to the inserted chromosomal III segment, and both transformed into strain LS255. Resulting transformants bearing the correct insertions as determined by Southern hybridization were then transformed with YEp51-GAL-FLP1 (Rose and Broach 1990), and individual isolates were cultured briefly in galactose-containing medium and plated on YEPD ( $2 \%$ yeast extract, $1 \%$ Bacto-peptone, $2 \%$ glucose). Isolates that had lost the YEp51-GAL-FLP1 plamid were screened by Southern hybridization for those that carried the inverted chromosome, and isolates with the correct structure were retained. Strains Y 2381 and $Y 2382$ were derived from strains $Y 2379$ and $Y 2380$ by transforming them to leucine prototrophy with plasmid pLS41, targeted by homologous recombination to the FRT site at the inversion breakpoint. Plasmid pLS41 consists of the cosmid vector pLAFR 1 carrying the yeast LEU 2 and FRT genes and 25-kb Caulobacter crescentus DNA.

Strains containing specific del etion of the recombination enhancer region of chromosome III were constructed by two-step replacements in strain Y2201. Large del etions were constructed in vitro by appropriate restriction digestion of a genomic fragment spanning the recombination enhancer from 28,542 to 31,609 and replacement of the deleted sequences with a 1.7-kb BamHI fragment spanning the yeast HIS3 gene. Del etion strains were constructed by transforming strain Y2201 to $\mathrm{His}^{+}$with EcoRI-digested DNA from the deletion/insertion plasmid. Smaller deletions of DPS1 and DPS2 were constructed by oligonucleotide mutagenesis of the genomic DN A corresponding to position 28,542-31,069 of chromosome III, cloned into plasmid pALTER (Promega), using the Altered Sites mutagenesis protocol as described by the manufacturer. The sequence of each mutation was designed to create a novel restriction site to facilitate subsequent identification of the mutation in yeast. All mutations were confirmed by PCR and restriction site analysis and then cloned into plasmid YIp5. Plamids carrying the desi red mutations were digested appropriately to target insertion into chromosome III and then used to transform strain Y 2201 to uracil prototrophy. U ra+ transformants were purified and plated onto SC plates [0.67\% Difco yeast nitrogen base, $2 \%$ glucose, amino acids, and nucleotide bases as specified (Rose et al. 1990)] containing 5'-fluoro-orotic acid (5-FOA) $(1.0 \mathrm{mg} / \mathrm{ml})$. 5-FOAresistant colonies were purified and then screened by Southern hybridization for those carrying the appropriate mutation(s).

Strains for analysis of cell type-specific transcription of the enhancer region were obtained by transforming diploid strains of the desired DPS1 DPS2 genotype to $\mathrm{Ura}^{+}$with plasmid pKSW72 cleaved with Eco47III. This plamid contains an allele of ho truncated at both the $5^{\prime}$ and $3^{\prime}$ ends and a copy of URA3 (Weiler et al. 1995). The resulting diploid strain, heterozygous for the dps allele and for the ho::URA3 allele, was sporulated and the spore clones tested by PCR analysis to determine the dps allele and by marker analysis for the ho::U RA3. Strains of the appropriate genotype were retained.

The levels of $\alpha 2 \mathrm{p} / \mathrm{Mcm} 1 \mathrm{p}$-mediated repression and $\mathrm{Mcm} 1 \mathrm{p}$ mediated activation by wild-type and mutant $\alpha 2 \mathrm{p} / \mathrm{Mcm} 1 \mathrm{p}$ binding sites were measured by expression of a heterologous CYC1-lacZ reporter plasmid. Plasmids containing the wildtype and mutant sites were constructed by inserting double- stranded oligonucleotides of the sites with TCGA overhangs into the Xhol site between the TATA and UAS elements in the CYC1-lacZ promoter of plasmid pTBA23 (Mead et al. 1996). Plasmids containing single oligonucleotide inserts were screened by restriction digests and verified by sequence analysis. To measure M cmlp-mediated activation, the CYCIUAS elements in the CYC1-lacZ promoter of these plasmids were deleted as described (Acton et al. 1997).

\section{Donor preference assays}

Tetrad dissection and determination of spore mating type were performed as described previously (Weiler and Broach 1992). The donor preference of the first offspring of an a or $\alpha$ spore to switch mating type was inferred by determining the predominant mating type cassette at the MAT locus in cells of the colony originating from that spore (Szeto and Broach 1997). Because both donor loci of the strains used in these assays contained inc mutations, the initial mating type switch precludes any subsequent switches in the progeny of the switched cell. Accordingly, the colony originating from a single spore should consist predominately of identical progeny from the first switching event, most often a switch carried out by the mother cell in the second generation. Determination of the predominant mating type allele resident at MAT in spore colonies was accomplished by PCR analysis of the MAT locus using primers that yielded different sized fragments for all four possible alleles-those initially resident at MAT and those derived from the silent loci. Colonies predominantly exhibiting matal $\delta 101$ all lele were scored as sel ecting HMR as donor, colonies predominantly exhibiting mat $\alpha 1 \alpha 2$ were scored as selecting $\mathrm{HML}$ as donor, and col onies that failed to exhibit one predominant al lele were scored as ambiguous. These latter colonies resulted either from diminished switching efficeincy, in which a significant number of cells carrying the original wild-type al lele resident at MAT are present in the colony, or from random donor preference, in which both donor loci are represented at MAT in cells in the colony. For spores originating from a parent heterozygous for a chromosome III inversion or mutation, spore clones were analyzed for the presence of the markers or by PCR analysis. Only colonies carrying the mutation or inversion were included in the analysis.

\section{Repression/activation assays}

To measure $\alpha 2 \mathrm{p} / \mathrm{M} \mathrm{cm} 1 \mathrm{p}$-mediated repression, pTBA23-derived plasmids containing individual $\alpha 2 \mathrm{p} / \mathrm{Mcm} 1 \mathrm{p}$ sites were transformed into yeast strains 246.1.1 and EG123 (Sicilano and Tatchell 1984), and the resultant transformants assayed for $\beta$-gal actosi dase activity (Goutte and Johnson 1988). The level of repression was determined by comparing the level of $\beta$-galactosidase expression observed in strain 246.1.1 carrying a test plasmid to that of strain EG 123 carrying the same plasmid. To measure $\mathrm{Mcm} 1 \mathrm{p}$-mediated activation, plasmids carrying the site of interest and lacking the CYC1 UAS were transformed into the yeast strain GY12 and individual transformants assayed for $\beta$-galactosidase activity (Acton et al. 1997). Activation levels were determined by comparing $\beta$-gal actosidase levels in transformants carrying the test plasmid to that of the same strain carrying a control plasmid lacking an $\alpha 2 \mathrm{p} / \mathrm{Mcm} 1 \mathrm{p}$ site. Assays were performed with three independent transformants for each plasmid, and the $\beta$-gal actosi dase units were averaged. Standard deviations were within $20 \%$. 


\section{Electrophoretic mobility shift assays}

The relative $\alpha 2 p / M c m 1 p ~ D N A$-binding affinities for the natural and mutant $\alpha 2 \mathrm{p} / \mathrm{Mcm} 1 \mathrm{p}$ sites were determined by electrophoretic mobility shift assays (EMSAs), as described (Zhong and Vershon 1997). Labeled DNA fragments used in EMSAs were synthesized by PCR amplification with label ed primers and purified by electrophoresis on a $10 \%$ native polyacrylamide gel. Labeled DNA fragments were incubated with purified $\alpha 2$ and $\mathrm{M} \mathrm{cml}_{1-96}$ proteins at the concentrations given in the legend to Figure 3 at room temperature for $3 \mathrm{hr}$. Both $\alpha 2$ and $\mathrm{M} \mathrm{cml}_{1-96}$ proteins were purified as described previously and were $>90 \%$ pure as judged by Coomassie-stained SDS-polyacrylamide (Vershon et al. 1993; Vershon and Johnson 1995). All binding reactions were electrophoresed through $0.5 \times \mathrm{TBE} / 4.5 \%$ native polyacylamide gels at $200 \mathrm{~V}$ for $2-3 \mathrm{hr}$. Gels were dried, exposed to phosphor screens, and images were scanned on a Molecular Dynamics Phorphorlmager model 425.

\section{Northern analysis}

Total RNA was prepared as described from yeast cells in exponential phase in YEPD, fractionated on agarose gels containing $8 \%$ formaldehyde, transferred to Hybond nylon membrane in high salt, and probed with the indicated DN A fragments labeled by random primer extension. Washed filters were exposed to phosphor screens, and images were scanned on a M ol ecular Dynamics Phosphorlmager model 425.

\section{Acknowledgments}

The research presented in this report was supported by grants from the $\mathrm{N}$ ational Institutes of Health to J.R.B. and A.K.V.

The publication costs of this article were defrayed in part by payment of page charges. This article must therefore be hereby marked "advertisement" in accordance with 18 USC section 1734 solely to indicate this fact.

\section{References}

Acton, T.B., H. Zhong, and A.K. Vershon. 1997. DNA-binding specificity of $\mathrm{Mcml}$ : Operator mutations that alter DNAbending and transcriptional activities by a MADS box protein. Mol. Cell. Biol. 17: 1881-1889.

Bobola, N., R.P. Jansen, T.H. Shin, and K. Nasmyth. 1996. Asymmetric accumulation of Ash1p in postanaphase nuclei depends on a myosin and restricts yeast mating-type switching in mother cells. Cell 85: 699-709.

Breeden, L. and K.A. Nasymth. 1985. Regulation of the yeast HO gene. Cold Spring Harbor Symp. Quant. Biol. 50: 643650.

Brown, C.J., B.D. Hendrich, J.L. Rupert, R.G. Lafreniere, Y. Xing, J. Lawrence, and H.F. Willard. 1992. The human XIST gene: Analysis of a $17 \mathrm{~kb}$ inactive X-specific RNA that contains conserved repeats and is highly local ized within the nucleus. Cell 71: 525-542.

Cooper, J.P., S.Y. Roth, and R.T. Simpson. 1994. The global transcriptional regulators, SSN 6 and TUP1, play distinct roles in the establishment of a repressive chromatin structure. Genes \& Dev. 8: 1400-1410.

Gerring, S.L., F. Spencer, and P. Hieter. 1990. The CHL1 (CTF1) gene product of Saccharomyces cervisiae is important for chromosome transmission and normal cell cycle progression in G2/M. EMBO J. 9: 4347-4358.
Goutte, C. and A.D. Johnson. 1988. al protein alters the DNA specificity of $\alpha 2$ repressor. Cell 52: 875-882.

Herskowitz, I., J. Rine, and J. Strathern. 1992. Mating-type determination and mating type interconversion in Saccharomyces cerevisiae. In The molecular and cellular biology of the yeast Saccharomyces (ed. E.W. Jones, J.R. Pringle, and J.R. Broach), pp. 583-656. Cold Spring Harbor Laboratory Press, Cold Spring Harbor, NY.

Jensen, R.E. and I. Herskowitz. 1984. Directionality and regulation of cassette substitution in yeast. Cold Spring Harbor Symp. Quant. Biol. 49: 97-104.

Jung, S., K. Rajewsky, and A. Radbruch. 1993. Shutdown of class switch recombination by deletion of a switch region control element. Science 259: 984-987.

Keleher, C.A., C. Goutte, and A.D. Johnson. 1988. The yeast cell-type specific repressor $\alpha 2$ acts cooperatively with a noncell-type-specific protein. Cell 53: 927-936.

Keleher, C.A., S. Passmore, and A.D. Johnson. 1989. Yeast repressor $\alpha 2$ binds to its operator cooperatively with yeast protein Mcm1. Mol. Cell. Biol. 9: 5228-5230.

Keleher, C.A., M.J. Redd, J. Schultz, M. Carlson, and A.D. Johnson. 1992. Ssn6-T up1 is a general repressor of transcription in yeast. Cell 68: 709-719.

Komachi, K., M.J. Redd, and C. Wolberger. 1994. The WD repeats of Tupl interact with the homeo domain protein $\alpha 2$. Genes \& Dev. 8: 2857-2867.

Kostriken, R. and F. Heffron. 1984. The product of the HO gene is a nuclease: Purification and characterization of the enzyme. Cold Spring Harbor Symp. Q uant. Biol. 49: 89-96.

Kostriken, R., J.N . Strathern, A.J.S. Klar, J.B. Hicks, and F. Heffron. 1983. A site-specific endonuclease essential for mating type switching in Saccharomyces cerevisiae. Cell 35: 167174.

Kotani, H., M.W. Germann, A. Andrus, R. Vinayak, B. Mullah, and E.B. Kmiec. 1996. RN A facilitates RecA-mediated DN A pairing and strand transfer between molecules bearing limited regions of homology. Mol. \& Gen. Genet. 250: 626-634.

Mead, J., H. Zhong, T.B. Acton, and A.K. Vershon. 1996. Yeast $\alpha 2$ and $\mathrm{Mcm} 1$ proteins interact through a region similar to $a$ motif found in homeodomain proteins in higher eukaryotes. Mol. Cell. Biol. 16: 2135-2143.

N asmyth, K.A. 1983. Molecular analysis of a cell lineage. Nature 302: 670-676.

Passmore, S., R. Elble, and B.K. Tye. 1989. A protein involved in minichromosome maintenance in yeast binds a transcriptional enhancer conserved in eukaryotes. Genes \& Dev. 3: 921-935.

Penny, G.D., G.F. Kay, S.A. Sheardown, S. Rastan, and N. Brockdorff. 1996. Requirement for Xist in X chromosome inactivation. Nature 379: 131-137.

Rastan, S. 1994. X chromosome inactivation and the Xist gene. Curr. Opin. Genet. Dev. 4: 292-297.

Rose, A.B. and J.R. Broach. 1990. Propagation and expression of cloned genes in yeast: $2-\mu \mathrm{m}$ circle-based vectors. Methods Enzymol. 185: 234-279.

Rose, M.D., F. Winston, and P. Hieter. 1990. Methods in yeast genetics: A laboratory course manual Cold Spring Harbor Laboratory Press, Cold Spring Harbor, NY.

Sauer, R.T., D.L. Smith, and A.D. Johnson. 1988. Flexibility of the yeast $\alpha 2$ repressor enables it to occupy the ends of its operator, leaving the center free. Genes \& Dev. 2: 807-816.

Siciliano, P.G. and K. Tatchell. 1984. Transcription and regulatory signals at the mating-type locus in yeast. Cell 37: 969-978.

Sil, A. and I. Herskowitz. 1996. Identification of an asymmetrically local ized determinant, Ash1p, required for lineage-specific transcription of the yeast HO gene. Cell 84: 711-722. 
Stanhope-Baker, P., K.M. Hudson, A.L. Shaffer, A. Constantinescu, and M.S. Schlissel. 1996. Cell type-specific chromatin structure determines the targeting of $\mathrm{V}(\mathrm{D}))$ recombinase activity in vitro. Cell 85: 887-897.

Strathern, J.N., A.J.S. Klar, J.B. Hicks, J.A. A braham, J.M. Ivy, K.A. N asmyth, and C. M CGill. 1982. Homothallic switching of yeast mating type cassettes is initiated by a doublestranded cut in the MAT Iocus. Cell 31: 183-192.

Szeto, L. and J.R. Broach. 1997. Role of $\alpha 2$ protein in donor locus selection during mating type interconversion. Mol. Cell. Biol. 17: 751-759.

Tanaka, K., T. Oshima, H. Araki, S. Harashima, and Y. Oshima. 1984. Mating type control in Saccharomyces cerevisiae: A frameshift mutation at the common DNA sequence, $X$, of the HML $\alpha$ locus. Mol. Cell. Biol. 4: 203-212.

Vershon, A.K. and A.D. Johnson. 1993. A short, disordered protein region mediates interaction between the homeodomain of the yeast $\alpha 2$ protein and the MCM 1 protein. Cell 72: 105112.

Vershon, A.K., Y. Jin, and A.D. Johnson. 1995. A homeo domain protein lacking specific side chains of helix 3 can still bind DNA and direct transcriptional repression. Genes \& Dev. 9: 182-192.

Weiler, K.S. and J.R. Broach. 1992. Donor locus selection during Saccharomyces cerevisiae mating type interconversion re sponds to distant regulatory signals. Genetics 132: 929-942.

Weiler, K.S., L. Szeto, and J.R. Broach. 1995. M utations affecting donor preference during mating type interconversion in Saccharomyces cerevisiae. Genetics 139: 1495-1510.

Wu, X. and J.E. Haber. 1995. MATa donor preference in yeast mating type switching: Activation of a large chromosomal region for recombination. Genes \& Dev. 9: 1922-1932.

- - - 1996. A 700 bp cis-acting region controls mating-type dependent recombination al ong the entire left arm of yeast chromosome III. Cell 87: 277-285.

Wu, X., J.K. Moore, and J.E. Haber. 1996. Mechanism of MAT $\alpha$ donor preference during mating-type switching of Saccharomyces. Mol. Cell. Biol. 16: 657-668.

Yancopoulos, G.D., R.A. DePinho, K.A. Zimmerman, S.G. Lutzker, N. Rosenberg, and F.W. Alt. 1986. Secondary genomic rearrangement events in pre-B cells: VHDJH replacement by a LINE-1 sequence and directed class switching. EMBO J. 5: 3259-3266.

Yoon, K., A. Cole-Strauss, and E.B. Kmiec. 1996. Targeted gene correction of episomal DNA in mammalian cells mediated by a chimeric RN A.DN A oligonucleotide. Proc. N atl. Acad. Sci. 93: 2071-2076.

Zhang, J., A. Bottaro, S. Li, V. Stewart, and F.W. Alt. 1993. A selective defect in IgG2b switching as a result of targeted mutation of the I gamma $2 \mathrm{~b}$ promoter and exon. EMBO J. 12: 3529-3537.

Zhong, H. and A.K. Vershon. 1997. The yeast homeodomain protein MAT $\alpha 2$ shows extended DNA binding specificity in complex with Mcm1. J. Biol. Chem. 272: 8402-8409. 


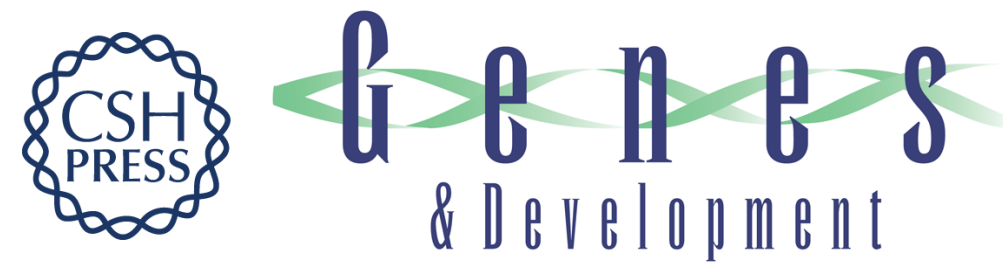

\section{$\alpha 2 p$ controls donor preference during mating type interconversion in yeast by inactivating a recombinational enhancer of chromosome III}

Lisa Szeto, Maria K. Fafalios, Hualin Zhong, et al.

Genes Dev. 1997, 11:

Access the most recent version at doi:10.1101/gad.11.15.1899

References

This article cites 40 articles, 20 of which can be accessed free at:

http://genesdev.cshlp.org/content/11/15/1899.full.html\#ref-list-1

License

Email Alerting

Receive free email alerts when new articles cite this article - sign up in the box at the top

Service right corner of the article or click here.

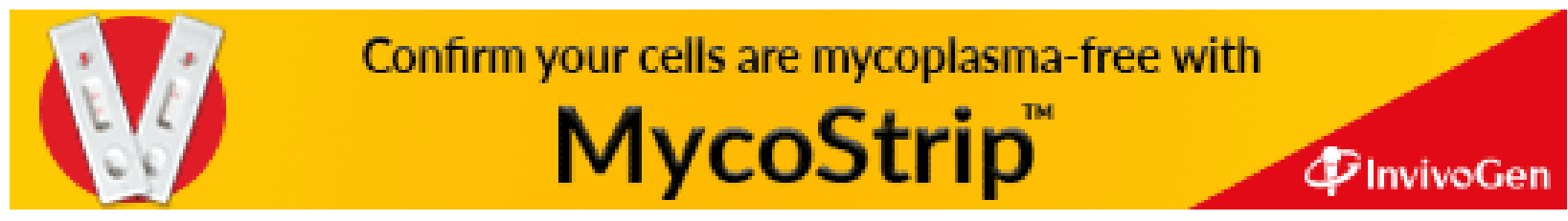

